Relations industrielles

Industrial Relations

\title{
Nos collaborateurs
}

Volume 3, numéro 2, octobre 1947

URI : https://id.erudit.org/iderudit/1024059ar

DOI : https://doi.org/10.7202/1024059ar

Aller au sommaire du numéro

\section{Éditeur(s)}

Département des relations industrielles de l’Université Laval

\section{ISSN}

0034-379X (imprimé)

1703-8138 (numérique)

Découvrir la revue

Citer cet article

(1947). Nos collaborateurs. Relations industrielles / Industrial Relations, 3(2),

31-31. https://doi.org/10.7202/1024059ar

Tous droits réservés @ Département des relations industrielles de l’Université Laval, 1947
Ce document est protégé par la loi sur le droit d'auteur. L’utilisation des services d'Érudit (y compris la reproduction) est assujettie à sa politique d'utilisation que vous pouvez consulter en ligne.

https://apropos.erudit.org/fr/usagers/politique-dutilisation/ 
Nous espérons que ces quelques données seront suffisantes pour permettre à notre correspondant de déterminer lui-même s'il a des droits en vertu des règlements municipaux ou en vertu de la loi des Maîtres et des serviteurs.$$
\text { LOGIQUE SOCIALE }
$$

L'Ecole sociale populaire vient de publier en brochure une lettre pastorale de S.Exc. Mgr Arthur Douville qui tout en datant de 1944 demeure toujours d'actualité. Tous ceux qui la connaissaient déjà se réjouiront de la diffusion qui lui sera faite. Ce document, en plus de rappeler certains principes de la doctrine sociale de l'Eglise, - élémentaires pour tous ceux qui sont mêlés à l'action sociale chez nous, mais grandement oubliés ou méconnus par un trop grand nombre, - relate une expérience nouvelle et intéressante dans le domaine des relations du travail. Il y est question de l'histoire et de l'organisation de la convention collective de travail qui règle les rapports existant entre les divers syndicats représentant les employés des fabriques et des institutions religieuses du diocèse de Saint-Hyacinthe et l'Association patronale qui groupe tous ces employeurs.

Ce n'est pas pour rien que l'auteur a intitulé son étude Logique sociale. Les souverains pontifes depuis soixante ans n'ont cessé de recommander aux travailleurs et aux employeurs de se grouper dans des associations professionnelles pour fixer sur une base de justice et de charité les droits et devoirs de chacun. «'L'Eglise prêche la justice du salaire et des conditions de travail; l'Eglise enseigne la collaboration nécessaire et sincère entre employeurs et employés; l'Eglise propose comme modes de collaboration l'association professionnelle et les comités mixtes; l'Eglise enfin demande à l'Etat de promouvoir une législation sociale, gardienne des intérêts de tous, mais surtout protectrice des intérêts des travailleurs ».

Cette réalisation de l'évêque de Saint-Hyacinthe dans son diocèse est plus qu'une oeuvre de logique: elle est une oeuvre apologétique auprès des travailleurs catholiques, comme aux yeux de tous ceux qui, sans partager notre foi ne sont pas indifférents à notre doctrine sociale. Comme on le comprend, il se défend bien de fixer une ligne de conduite à qui que ce soit, mais tous ceux qui ont à coeur l'établissement des relations du travail dans la justice et la charité souhaitent avec ardeur qu'en tenant compte des circonstances propres à chaque milieu cette expérience ne reste pas locale.

C'est une brochure à lire, à méditer et qui peut être très utile à passer. - Gérard Dion

(1) Logique sociale. S.Exc. Mgr Douville, évêque de Saint-Hyacinthe. Une brochure, 29 pages, Ecole sociale populaire, no 404 , septembre 1947.

\section{BIBLIOGRAPHIES}

Jacques Cousineau, s.J., Promotion ouvrière, dans Relations, octobre 1947, pp. 294-296.

Dans cet article solidement appuyé par de nombreuses citations, l'anteur qui est bien connu dans les relations du travail, expose en termes clairs et non équivoques, un problème de la plus haute importance au point de vue moral et psychologique. Si nos employeurs ne veulent pas, comme ceux d'autres pays, être pris par surprise. ils feraient bien de commencer dès maintenant à étudier et à réaliser graduellement la participation ouvrière aux responsabilités de l'entreprise.
Emile Bouvifr, S.J., La co-gestion des entreprises, dans l'Actualité économique, vol. 23 , no 3 , octobre 1947 , pp. 40:3-420.

Dans cet article, l'auteur, directeur de la section des relations industrielles de l'Université de Montréal, aborde la question si importante de la réforme de structure dans l'entreprise. Après avoir admis cette nécessité, il se borne à expliquer la participation à la gestion en s'appuyant sur des auteurs dont les thèses sont aujourd'hui dépassées, comme les RR.PP. Muller, s.j., et Du Passage, s.j., qu'il met en opposition avec d'autres sociologues tels que Charvet, les RR.PP. Chenu, o.p., Desbuquois, s.j. et Desquerat, s.j. Il ne cite pas les derniers documents pontificaux de Pie XII. Il en conclut à une participation bénigne à la gestion par une réforme de structure pluss apparente que réelle. Article très intéressant, mais il faudra revenir sur ce sujet dans le Bulletin.

G. D.

Confédération des Syndicats Chrétiens, Cogestion, Notre politique familiale, Le Syndicalisme, Rapports des Commissions d'Etudes de la C.S.C.

Ces trois rapports publiés en brochure séparée ont été présentés au XVe Congrès de la Confédération des Syndicats Chrétiens tenu à Bruxelles les 10,11 et 12 octobre 1947. Le premier, la Cogestion est le fruit du travail en collaboration des dirigeants de la C.S.C. et de plusieurs professeurs de Louvain; il contient sept chapitres: 1-le progrès technique, la modernisation et les travailleurs; 2-les droits du travail à la cogestion; 3-l'organisation paritaire de l'économie; 4 -la répression des abus de puissances économiques et financières; 5-les conseils d'entreprise; 6-la réforme de la S.A. et de la S.P.R.L.; 7 -au delà du salariat.

Le second et le troisième ont été préparés par les dirigeants de la C.S.C. seulement. Dans Notre politique familiale on trouve: 1-les bases d'une politique familiale; 2-les allocations familiales; 3-les frais minima d'entretien des ménages de travailleurs; 4-la place de la mère et de l'épouse dans notre politique familiale; 5-la structure et la gestion des caisses de compensation; 6-le problème du logement; 7-la famille et les dégrèvements fiscaux.

Le rapport sur Le Syndicalisme traite des questions suivantes: 1-première évolution du Syndicalisme; 2-le syndicalisme après la libération; 3-la position actuelle du syndicalisme; 4 -le syndicalisme dans les rouages de l'Administration; 5-les nouvelles positions; 6-le syndicalisme libre dans l'Etat démocratique.

On y constate le souci de cet important groupement de travailleurs chrétiens de Belgique d'appuyer son action sur des études sérieuses. Les centrales oúvrières canadiennes auraient intérêt à préparer leurs congrès de la même façon.

\section{NOS COLLABORATEURS}

Choletre, Gaston, B.A., M.Sc.Soc., chef du secrétariat du Comité diocésain d'Action catholique, Québec.

Ouellet, J.-Médard, secrétaire de l'Association patronale de Québec et secrétaire-trésorier du Comité paritaire de l'alimentation en gros de Québec et du Comité conjoint des barbiers-coiffeurs de Québec.

DesprÉs, Jean-Pierre, D.Sc.Soc., membre du personnel du Bureau international du Travail à Genève, professeur à la Faculté des sciences sociales de l'Université Laval.

GAGNÉ, Jean, B.A., B.Sc.Soc., LL.L., assistant-secrétaire du Département des relations industrielles de l'Universite Laval.

Quimper, Donat, B.A., LL.L., directeur-adjoint du Service de conciliation et d'arbitrage du ministère du Travail. 